\title{
Quinoline-Based Materials: Spectroscopic Investigations as well as DFT and TD-DFT Calculations
}

\author{
Mahmoud A. S. Sakr $\mathbb{D}^{1},{ }^{1}$ Samy A. El-Daly $\mathbb{D}^{2},{ }^{2}$ El-Zeiny M. Ebeid $\mathbb{D},,^{1,2}$ \\ Sadeq M. Al-Hazmy $\mathbb{D}^{3,4}$ and Mohammed Hassan $\mathbb{D D}^{5}$ \\ ${ }^{1}$ Misr University of Science and Technology (MUST), $6{ }^{\text {th }}$ October City, Egypt \\ ${ }^{2}$ Chemistry Department, Faculty of Science, Tanta University, Tanta, Egypt \\ ${ }^{3}$ Advance Diagnostic and Progressive Human Care Research Group, School of Biomedical Engineering and Health Science, \\ University Technology Malaysia, Johor Bahru, Malaysia \\ ${ }^{4}$ Chemistry Department, Faculty of Science, Qassim University, Qassim, Saudi Arabia \\ ${ }^{5}$ Ibb University, Faculty of Science, Chemistry Department, Ibb, Yemen
}

Correspondence should be addressed to Mohammed Hassan; m-hassan@ibbuniv.edu.ye

Received 12 November 2021; Revised 31 December 2021; Accepted 11 January 2022; Published 29 January 2022

Academic Editor: Davut Avci

Copyright (c) 2022 Mahmoud A. S. Sakr et al. This is an open access article distributed under the Creative Commons Attribution License, which permits unrestricted use, distribution, and reproduction in any medium, provided the original work is properly cited.

\begin{abstract}
Quinoline derivatives such as 15,15-difluoro-[1,3,2] diaazaborininodiquinoline (DDP) and 15,15-difluoro-[1,3,2] diaazaborininodiquinoline acetonitrile (DDPA) have a range of biological and medical activities. So, it is vital to shed light on these compounds in terms of their optical properties supported by quantum calculations. The absorption and emission spectra of studied compounds were measured within the laboratory, whereas the quantum calculations were performed utilizing the density functional theory (DFT) calculations. Additionally, the time-dependent density functional theory (TD-DFT) was applied for the comparison of some sensible results with the theoretical ones. The molecular structures of these compounds were presented via applying chemical analysis techniques. The electronic absorption spectra of DDP and DDPA molecular structures were monitored through an experiment in hosts such as carbon tetrachloride $\left(\mathrm{CCl}_{4}\right)$, chloroform $\left(\mathrm{CHCl}_{3}\right)$, methylene dichloride $\left(\mathrm{CH}_{2} \mathrm{Cl}_{2}\right)$, acetone, and dimethyl sulfoxide (DMSO). Also, the influence of $\mathrm{pH}$ on the absorption spectra of the DDP molecule was studied. The molecular structures of these quinoline derivatives have been optimized via utilizing the B3LYP/6-31G (d) level of theory. The electronic absorption and emission spectra of the DDP compound in gas, THF, and DMSO have been calculated utilizing TD-DFT at the CAM-B3LYP/6-31G $++(\mathrm{d}, \mathrm{p})$ level.
\end{abstract}

\section{Introduction}

Quinoline is a heterocyclic compound with few chemical applications on its own. However, several of its derivatives have numerous applications such as pharmaceutical preparations [1], agricultural chemistry [2], materials and dyes [3], as well as in medicine. Recently, the nucleus of quinoline and plenty of its derivatives grasped interest to chemists and biologists owing to their many and necessary applications within the field of medicine as a number of them are used as antituberculosis $[1,4,5]$, antimalarial [6], anticancer [7], antibiotic [8], hypotensive, antiviral [1], antioxidant [9], and antifungal [10]. Given the wide importance of quinoline derivatives, it is absolutely necessary to shed light on them during this analysis.

Liquid quinoline dye lasers have significantly high potency, low optical device threshold, wide calibration varying from the near-ultraviolet to near-infrared spectral region, and long life $[11,12]$. None of the opposite lasers will replace dye lasers for their strength, gain, low price, and big selection of viability [13]. However, these lasers cannot enter the industrialized market due to their inherent defects such as massive size, inflammable and cytotoxic solvents, dye deterioration, heating, and triplet state formation [14]. The dye 
optical device resolution ought to flow through the optical device cavity to keep up stable gain and beam quality. This needs an outside variety of dye flow systems and reservoirs, and an outside quantity of dye is dissolved in typically inflammable and cytotoxic solvents [11-13, 15-17].

The electronic absorption spectra of DDP dye at completely different $\mathrm{pH}$ values show clear isosbestic points in their absorption spectra indicating the existence of two substances in equilibrium with each other [12, 18-21] showing an isosbestic point. However, the presence of associated degree isosbestic point is not a continuous proof of the existence of solely two compounds because the third absorbing species might have zero absorptivity at this specific wavelength [22].

The main objective of the study in this manuscript is the spectroscopic investigations and computational calculations of compounds under study using the DFT method followed by the determination of the accurate functional as well as the basis set using TD-DFT to arrive at the accurate theoretical results and comparing them with the experimental ones.

\section{Materials and Methods}

2.1. Materials' Preparation. 15,15-Difluoro-[1,3,2] diaazaborininodiquinoline (DDP) and 15,15-difluoro-[1,3,2] diaazaborininodiquinoline acetonitrile (DDPA) were provided by Professor Dr. Ewald Daltrozzo of Konstanz University, Germany, and used without further purification. All solvents employed in this work were of chemical analysis grade and were preliminary checked for the absence of absorbing or fluorescent impurities among the scanned spectral ranges. UV-Vis electronic absorption spectra were obtained utilizing a Shimadzu UV-Vis 1650-PC spectrophotometer, and steady-state fluorescence spectra were presented employing a quartz cuvette of $0.2 \mathrm{~cm}$ path length to minimize the reabsorption of emitted photons; the emission was monitored at $90^{\circ}$ geometry using a Jasco FP8200 spectrofluorometer, excitation bandwidth $5 \mathrm{~nm}$ and emission bandwidth $5 \mathrm{~nm}$, with a Xe lamp light source.

2.2. Methodology and Theoretical Calculations. Upon usage of density functional theory (DFT) and time-dependent density functional theory (TD-DFT) strategies, the ground electronic structure and excited state structures of the probe dye area unit were improved using the Gaussian 09 package [23]. The molecular structures under study have been optimized employing [24-26] the DFT/B3LYP/6-31G (d) level of theory. The electronic absorption and emission spectra of the quinoline derivatives in numerous solvents have been calculated exploiting the TD-DFT [27] at the CAM-B3LYP/ 6-31G ++(d, p) level.

\section{Results and Discussion}

3.1. DFT Calculations. The optimized molecular structures for DDP and DDPA molecules within the gaseous state area unit were obtained by the utilization of the B3LYP/6-31G (d) level of theory. The obtained results are shown in Figure 1. Some necessary calculated and optimized geometrical parameters such as bond length (BL) in $\AA$ and bond angle (BA) and dihedral angle (DA) in degree $\left({ }^{\circ}\right)$ were computed for DDP and DDPA in gas at the ground $\left(\mathrm{S}_{0}\right)$ and initial excited state $\left(\mathrm{S}_{1}\right)$ using B3LYP/6-31G (d) level of theory; the obtained results are tabulated in Table 1. The labeling scheme for the studied molecular structures is shown in Figure 1. DFT was used to obtain the ground state $(G)$ molecular structure of DDPA and DDP in the gaseous state. Also, TDDFT was applied to obtain electronic excited state (Exc.) molecular modeling structures for DDP and DDPA in the gaseous phase. The optimized electronic ground and excited molecular structures were obtained via applying the B3LYB/ 6-31G (d) level of theory. As presented in Table 1 and Figure 1, the BLs $\left(\mathrm{C}_{2}-\mathrm{C}_{3}\right.$ and $\left.\mathrm{C}_{1}-\mathrm{C}_{31}\right)$ for the DDPA compound and $\left(\mathrm{C}_{3}-\mathrm{C}_{4}\right.$ and $\left.\mathrm{C}_{13}-\mathrm{N}_{32}\right)$ for DDP increase from $\mathrm{G}$ to Exc., and the difference values are 0.014 and $0.001 \AA$ for DDPA and 0.021 and $0.006 \AA$ for DDA. On the contrary, $\left(\mathrm{C}_{2}-\mathrm{N}_{38}\right.$ and $\left.\mathrm{N}_{37}-\mathrm{C}_{18}\right)$ BLs for DDPA and $\left(\mathrm{C}_{3}-\mathrm{N}_{34}\right.$ and $\mathrm{N}_{33^{-}}$ $\mathrm{C}_{19}$ ) BLs for DDA were shortened from $\mathrm{S}_{0}$ to $\mathrm{S}_{1}$ state. The difference values are 0.014 and $0.015 \AA$ for DDPA and DDA, respectively. The DAs $\left(\mathrm{C}_{12}-\mathrm{C}_{7}-\mathrm{C}_{2}-\mathrm{C}_{38}, \mathrm{C}_{31}-\mathrm{C}_{28}-\mathrm{N}_{37}-\mathrm{C}_{18}\right.$, $\mathrm{C}_{27}-\mathrm{C}_{24}-\mathrm{C}_{19}-\mathrm{C}_{20}$ and $\left.\mathrm{B}_{32}-\mathrm{N}_{37}-\mathrm{C}_{18}-\mathrm{C}_{19}\right)$ for DDPA and $\left(\mathrm{C}_{1}\right.$ $\mathrm{C}_{2}-\mathrm{C}_{3}-\mathrm{N}_{34}, \mathrm{C}_{19}-\mathrm{N}_{33}-\mathrm{C}_{28}-\mathrm{N}_{32}, \mathrm{C}_{29}-\mathrm{C}_{25}-\mathrm{C}_{18}-\mathrm{C}_{17}$ and $\mathrm{B}_{31}-\mathrm{N}_{33^{-}}$ $\mathrm{C}_{19^{-}}-\mathrm{C}_{18}$ ) for DDP are $179.99^{\circ}$ in the $\mathrm{G}$ and Exc. states. This is referring to the planar molecular structures for DDPA and DDP compounds in both $\mathrm{G}$ and Exc. states. The BAs $\left(\mathrm{C}_{11^{-}}\right.$ $\mathrm{C}_{12}-\mathrm{C}_{7}, \mathrm{C}_{7}-\mathrm{C}_{2}-\mathrm{C}_{3}$ and $\left.\mathrm{N}_{38}-\mathrm{B}_{32}-\mathrm{N}_{37}\right)$ for DDPA are increased via $0.04,0.2$, and 1.26 , respectively, upon excitation from $S_{0}$ to $\mathrm{S}_{1}$ state. On the contrary, the $\mathrm{BAs}\left(\mathrm{C}_{2}-\mathrm{N}_{38}-\mathrm{C}_{1}\right.$ and $\mathrm{N}_{38}-\mathrm{C}_{1}$ $\left.\mathrm{C}_{31}\right)$ for DDPA and $\left(\mathrm{C}_{6}-\mathrm{C}_{1}-\mathrm{C}_{2}, \mathrm{C}_{2}-\mathrm{C}_{3}-\mathrm{C}_{4}, \mathrm{C}_{3}-\mathrm{N}_{34}-\mathrm{C}_{13}\right.$ and $\mathrm{N}_{34}-\mathrm{C}_{13}-\mathrm{N}_{32}$ ) for DDP are shortened upon excitation from $S_{0}$ to $S_{1}$ state. The BAs for studied molecular structures in G and Exc. states indicate $\mathrm{sp}^{2}$ hybridization.

The DDP and DDPA molecular modeling graphical presentation of the molecular orbitals HOMO $(\mathrm{H}) / \mathrm{LUMO}$ (L), $\mathrm{H}-1 / \mathrm{L}+1, \mathrm{H}-/ \mathrm{L}+$ together with their respective energy gaps (Egs) in the gaseous state were made via applying the B3LYP/6-31G (d) level of theory. The energy gaps go as follows: $\mathrm{H}$ and $\mathrm{L}\left(\mathrm{E}_{\mathrm{g} 1}\right), \mathrm{H}-1$ and $\mathrm{L}+1\left(\mathrm{E}_{\mathrm{g} 2}\right)$, and $\mathrm{H}-2$ and $\mathrm{L}+2\left(\mathrm{E}_{\mathrm{g} 3}\right)$ in the gaseous state via applying the B3LYP/6-31G (d) level of theory. The obtained results are presented in Figure 2. The energy values of $\mathrm{H}\left(\mathrm{E}_{\mathrm{H}}\right), \mathrm{L}\left(\mathrm{E}_{\mathrm{L}}\right), \mathrm{H}-1\left(\mathrm{E}_{\mathrm{H}-1}\right)$, $\mathrm{L}+1\left(\mathrm{E}_{\mathrm{L}+1}\right), \mathrm{H}-2\left(\mathrm{E}_{\mathrm{H}-2}\right)$, and $\mathrm{L}+2\left(\mathrm{E}_{\mathrm{L}+2}\right)$ are presented in Figure 2. Also, the $E_{g}$ values among the following, $\mathrm{H}$ and $\mathrm{L}$ $\left(\mathrm{E}_{\mathrm{g} 1}\right), \mathrm{H}-1$ and $\mathrm{L}+1\left(\mathrm{E}_{\mathrm{g} 2}\right)$, and $\mathrm{H}-2$ and $\mathrm{L}+2\left(\mathrm{E}_{\mathrm{g} 3}\right)$, in the gaseous state are listed in Figure 2. Due to hyperconjugation of the studied molecular structures, the HOMO MOs and lone pairs of electrons of nitrogen and fluoride atoms are delocalized over the whole DDP and DDPA molecular structures. On the contrary, the LUMO MOs are delocalized over the whole DDP and DDPA molecular modeling structures, while the lone pairs of electrons of fluoride and nitrogen $\left(\mathrm{N}_{35}\right.$ for DDPA and $\mathrm{N}_{32}$ for DDP) atoms are not contributed. The energy gap $\left(\mathrm{E}_{\mathrm{g} 1}\right)$ value is calculated by applying the difference $\left(\mathrm{E}_{\mathrm{L}}-\mathrm{E}_{\mathrm{H}}\right)$. The calculated $\mathrm{E}_{\mathrm{g} 1}$ value for DDP and DPPA compounds increases in the order DDP $<$ DDPA indicating that the DDP molecular modeling structure is more reactive compared to the DDPA molecular structure. When the magnitude of $\mathrm{E}_{\mathrm{g}}$ increases, the kinetic 

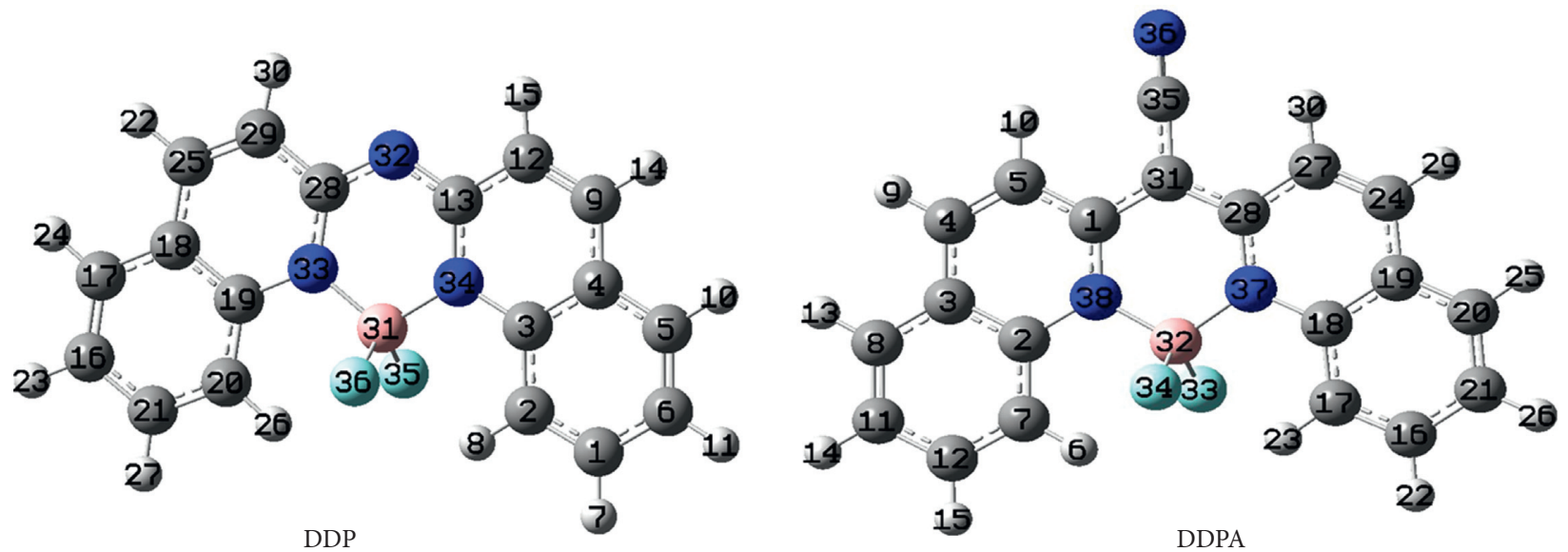

Figure 1: Optimized molecular structures for DDP and DDPA compounds in the gaseous state employing the B3LYP/6-31G (d) level of theory.

TABLE 1: Selected optimized geometrical parameters (bond length (BL) in $\AA$ and bond angle (BA) and dihedral angle (DA) in degree) computed for DDP and DDPA in the gaseous state at the ground $\left(\mathrm{S}_{0}\right)$ and initial excited state $\left(\mathrm{S}_{1}\right)$ employing the B3LYP/6-31G $(\mathrm{d})$ level of theory. For labeling, refer to Figure 1.

\begin{tabular}{|c|c|c|c|c|c|}
\hline \multirow{2}{*}{ Designation } & \multicolumn{2}{|c|}{ DDPA } & \multirow{2}{*}{ Designation } & \multicolumn{2}{|c|}{ DDP } \\
\hline & $\mathrm{S}_{0}$ & $\mathrm{~S}_{1}$ & & $\mathrm{~S}_{0}$ & $\mathrm{~S}_{1}$ \\
\hline $\mathrm{C}_{2}-\mathrm{C}_{3}$ & 1.426 & 1.440 & $\mathrm{C}_{3}-\mathrm{C}_{4}$ & 1.426 & 1.447 \\
\hline $\mathrm{C}_{2}-\mathrm{N}_{38}$ & 1.413 & 1.405 & $\mathrm{C}_{3}-\mathrm{N}_{34}$ & 1.410 & 1.395 \\
\hline $\mathrm{C}_{1}-\mathrm{C}_{31}$ & 1.422 & 1.443 & $\mathrm{C}_{13}-\mathrm{N}_{32}$ & 1.346 & 1.352 \\
\hline $\mathrm{N}_{37}-\mathrm{C}_{18}$ & 1.413 & 1.405 & $\mathrm{~N}_{33}-\mathrm{C}_{19}$ & 1.410 & 1.395 \\
\hline $\mathrm{C}_{11}-\mathrm{C}_{12}-\mathrm{C}_{7}$ & 121.15 & 121.19 & $\mathrm{C}_{6}-\mathrm{C}_{1}-\mathrm{C}_{2}$ & 121.38 & 121.19 \\
\hline $\mathrm{C}_{7}-\mathrm{C}_{2}-\mathrm{C}_{3}$ & 118.57 & 118.77 & $\mathrm{C}_{2}-\mathrm{C}_{3}-\mathrm{C}_{4}$ & 118.89 & 118.60 \\
\hline $\mathrm{C}_{2}-\mathrm{N}_{38}-\mathrm{C}_{1}$ & 120.87 & 120.41 & $\mathrm{C}_{3}-\mathrm{N}_{34}-\mathrm{C}_{13}$ & 120.84 & 120.12 \\
\hline $\mathrm{N}_{38}-\mathrm{C}_{1}-\mathrm{C}_{31}$ & 120.30 & 118.68 & $\mathrm{~N}_{34}-\mathrm{C}_{13}-\mathrm{N}_{32}$ & 123.42 & 121.97 \\
\hline $\mathrm{N}_{38}-\mathrm{B}_{32}-\mathrm{N}_{37}$ & 112.78 & 114.04 & $\mathrm{~N}_{34}-\mathrm{B}_{31}-\mathrm{N}_{33}$ & 110.40 & 112.33 \\
\hline $\mathrm{C}_{12}-\mathrm{C}_{7}-\mathrm{C}_{2}-\mathrm{C}_{38}$ & 179.99 & 179.99 & $\mathrm{C}_{1}-\mathrm{C}_{2}-\mathrm{C}_{3}-\mathrm{N}_{34}$ & 179.99 & 179.99 \\
\hline $\mathrm{C}_{31}-\mathrm{C}_{28}-\mathrm{N}_{37}-\mathrm{C}_{18}$ & 179.99 & 179.99 & $\mathrm{C}_{19}-\mathrm{N}_{33}-\mathrm{C}_{28}-\mathrm{N}_{32}$ & 179.99 & 179.99 \\
\hline $\mathrm{C}_{27}-\mathrm{C}_{24}-\mathrm{C}_{19}-\mathrm{C}_{20}$ & 179.99 & 179.99 & $\mathrm{C}_{29}-\mathrm{C}_{25}-\mathrm{C}_{18}-\mathrm{C}_{17}$ & 179.99 & 179.99 \\
\hline $\mathrm{B}_{32}-\mathrm{N}_{37}-\mathrm{C}_{18}-\mathrm{C}_{19}$ & 179.99 & 179.99 & $\mathrm{~B}_{31}-\mathrm{N}_{33}-\mathrm{C}_{19}-\mathrm{C}_{18}$ & 179.99 & 179.99 \\
\hline
\end{tabular}

stability of the molecule increases, and chemical reactivity decreases [28]. Hence, the kinetic stability of the DDPA molecule is higher than DDP in the gaseous phase as shown in Figure 2.

Some significant quantum parameters such as dipole moment $(\mu)$, chemical potential $(\rho)$, electronegativity $(\chi)$, and chemical hardness $(\eta)$ were calculated from the energy values of Lumo (EL) and Homo (EH) molecular orbitals by applying the following equations: $\rho=\left(E_{H}+E_{L}\right) / 2$ [23, 24], $\chi=-\left(E_{H}+E_{L}\right) / 2$, and $\eta=\left(E_{L}-E_{H}\right) / 2[23,25]$. Generally, once the chemical structure possesses high dipole moment, it acquires a large asymmetry in the electric charge distribution, and then it can be highly sensitive due to the change of molecular structure and electronic properties under an external electric field. Thus, as shown in Table 2 , the $\mu$ value of the compound DDPA is high compared to the DDP compound; therefore, this compound is more active compared to the DDP molecular structure. As conferred in Table 2, the $\rho$ value of the DDP molecular structure is lower compared to the opposite DDPA compound. This indicates that the escaping electrons from the DDP molecular structure are low compared to the DDPA molecule. Also, the high $\chi$ value for the DDP molecular structure compared to the DDPA compound (see Table 2) results in the power of this compound to draw in electrons from different compounds [29]. On the contrary, the $\eta$ value for the DDP molecular structure is high compared to DDPA (see Table 2). This means that the DDP compound is very difficult to liberate electrons, whereas the DDPA molecular structure is a good candidate to give electrons to another acceptor molecule.

3.2. Experimental UV-Vis Absorption Spectra. Experimental (Exp.) normalized absorption spectra $\left(1 \times 10^{-5} \mathrm{M}\right)$ for DDP (Figure 3(a)) and DDPA (Figure 3(b)) in several solvents are obtained; the obtained results are shown in Figures 3(a) and 3(b). The Exp. maximum absorption wavelength $\lambda_{\mathrm{abs}}$ (Exp.) in several solvents for DDP and DDPA molecular structures' area unit is tabulated in Table 3. The two and three maximum absorption wavelengths of DDP and DDPA molecular structures were 


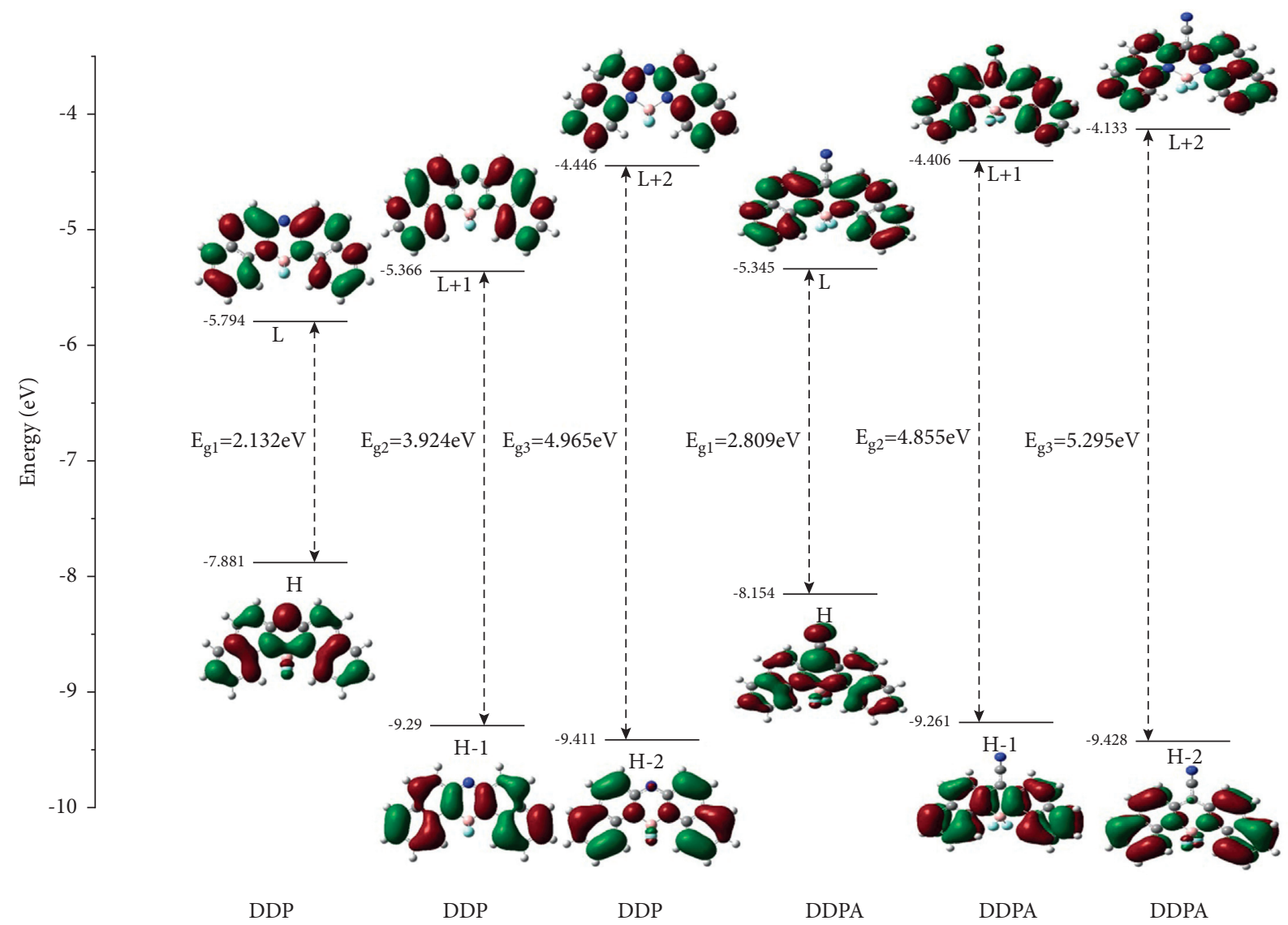

FIGURE 2: DDP and DDPA molecular modeling graphical presentation of HOMO (H)/LUMO (L) orbitals, $\mathrm{H}-1 / \mathrm{L}+1$, and $\mathrm{H}-2 / \mathrm{L}+2$ and the energy gap of $\mathrm{H} / \mathrm{L}\left(\mathrm{E}_{\mathrm{g} 1}\right), \mathrm{H}-1 / \mathrm{L}+1\left(\mathrm{E}_{\mathrm{g} 2}\right)$, and $\mathrm{H}-2 / \mathrm{L}+2\left(\mathrm{E}_{\mathrm{g} 3}\right)$ in the gas state via utilizing the B3LYP/6-31G (d) level of theory.

TABLE 2: Calculated HOMO energy $\left(\mathrm{E}_{\mathrm{H}}\right)$, LUMO energy $\left(\mathrm{E}_{\mathrm{L}}\right)$, energy gap $\left(\mathrm{E}_{\mathrm{g} 1}\right)$, dipole moment $(\mu)$, and other quantum parameters such as electronegativity $(\chi)$, chemical potential $(\rho)$, and chemical hardness $(\eta)$ of DDP and DDPA molecular structures in the gaseous state obtained and obeying the B3LYP/6-31G (d) level of theory.

\begin{tabular}{lccccccc}
\hline Compounds & $\mathrm{E}_{\mathrm{H}}(\mathrm{eV})$ & $\mathrm{E}_{\mathrm{L}}(\mathrm{eV})$ & $\mathrm{E}_{\mathrm{g} 1}(\mathrm{eV})$ & $\mu(\mathrm{D})$ & $\chi(\mathrm{eV})$ & $\rho(\mathrm{eV})$ & $\eta(\mathrm{eV})$ \\
\hline DDPA & -8.154 & -5.345 & 2.809 & 1.503 & -6.749 & 6.749 & 1.404 \\
DDP & -7.881 & -5.749 & 2.132 & 2.153 & -6.815 & 6.815 & 1.066 \\
\hline
\end{tabular}

obtained by applying completely different solvents such as $\mathrm{CCl}_{4}, \mathrm{CHCl}_{3}, \mathrm{CH}_{2} \mathrm{Cl}_{2}$, acetone, and DMSO as presented in Figures 3(a) and 3(b) because of $\pi-\pi^{*}$ electronic transition and increasing electronic vibrations in the $S_{1}$ state. The values of maximum absorption wavelengths of DDP and DDPA molecular structures modified from one solvent to another are different because of solute/solvent interactions.

3.3. TD-DFT Calculations. Via applying the Gaussian 09 program, the best DFT functional of the DDP molecule is studied using the 6-31G (d) basis set. Also, the best basis set of the same molecule was investigated utilizing CAM-B3LYP DFT functional. Therefore, the best DFT functional and the basis set for calculating the optical properties of the DDP and DDPA molecules were CAM-B3LYP/6-311G++ (d, p). Upon utilizing the TD-DFT technique and CAM-B3LYP/6-311G++ $(\mathrm{d}, \mathrm{p})$ level of theory, the calculated UV-Vis absorption and emission spectra of the DDP molecule in different solvents such as gaseous phase, THF, and DMSO are illustrated and compared with the obtained spectra recorded in Figure 4. The electronic calculated UV-Vis absorption spectrum of the DDP molecule in various solvents has three maximum absorption wavelengths (see Figure 4). The three maximum absorption wavelengths $\left(\lambda_{\text {max. }}\right)$ of the DDP dye in the gaseous phase are 210,265 , and $391 \mathrm{~nm}$. In the THF solvent, the three calculated

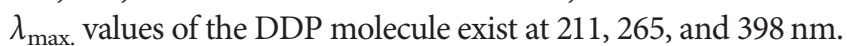
And in DMSO, the four $\lambda_{\max }$ absorption values are 183, 211, 265 , and $398 \mathrm{~nm}$ matching the three and four maximum absorption wavelengths of the DDP molecular structure by applying gas, THF, and DMSO being of $\pi-\pi^{*}$ electronic transition at increasing electronic vibrational in the $S_{1}$ state. Depending on the polarity of solvents, the absorption maximum bands for the DDP molecule in THF and DMSO are redshifted compared to the gas state as shown in Figure 4.

For DDP dye in different solvents, the calculated electronic emission spectra have only one band of maximum emission wavelength $\left(\lambda_{\text {max. }}\right)$ between 413 and $438 \mathrm{~nm}$, depending on the 


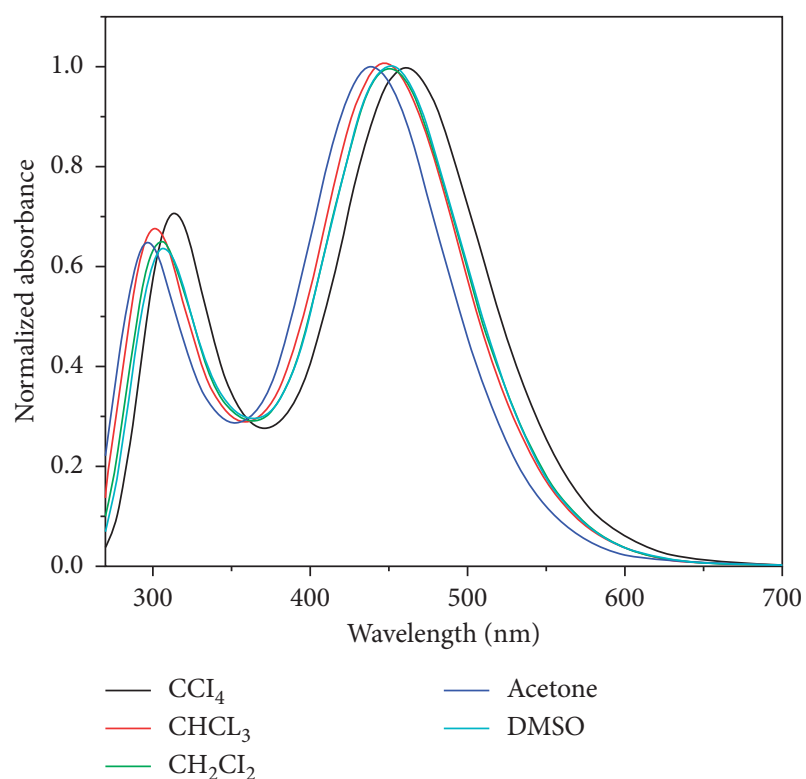

(a)

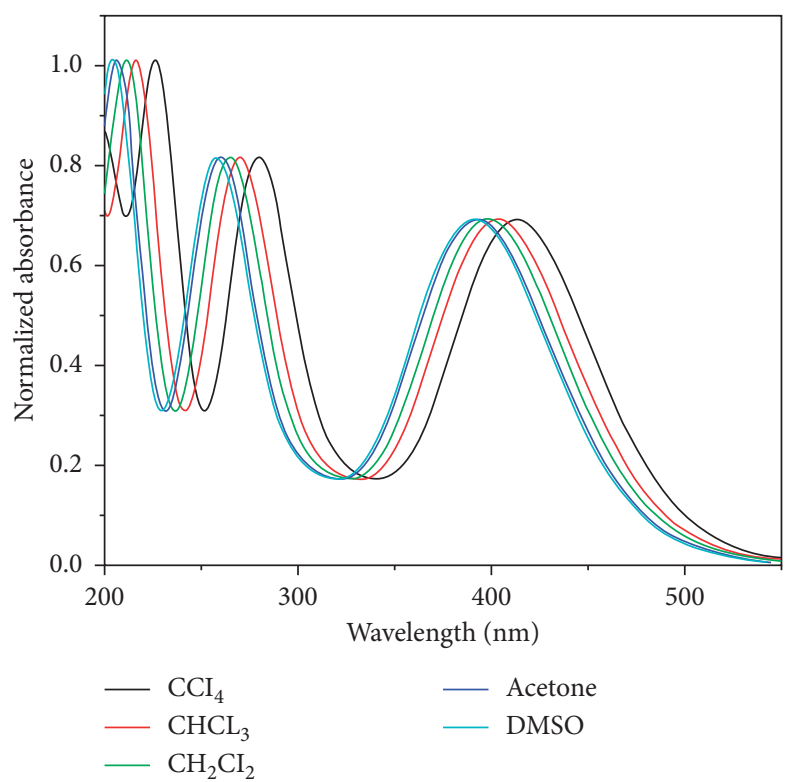

(b)

FIGURE 3: Experimental normalized absorption spectra $\left(1 \times 10^{-5} \mathrm{M}\right)$ for DDP (a) and DDPA (b) in different solvents.

TABle 3: Experimental maximum absorption wavelengths $\lambda_{\text {abs }}($ Exp.) in different solvents for DDP and DDPA molecular structures.

\begin{tabular}{llrccc}
\hline Solvents & \multicolumn{2}{c}{$\begin{array}{c}\lambda_{\text {abs }}(\text { Exp.) } \\
(\mathrm{nm})\end{array}$} & \multicolumn{3}{c}{$\lambda_{\text {abs }}$ (Exp.) $(\mathrm{nm})$ for } \\
DDPA & \\
\hline $\mathrm{CCl}_{4}$ & 313 & 462 & 226 & 280 & 413 \\
$\mathrm{CHCl}_{3}$ & 300 & 446 & 404 & 269 & 404 \\
$\mathrm{CH}_{2} \mathrm{Cl}_{2}$ & 305 & 449 & 211 & 264 & 340 \\
Acetone & 295 & 440 & 206 & 260 & 395 \\
DMSO & 303 & 450 & 204 & 259 & 389 \\
\hline
\end{tabular}

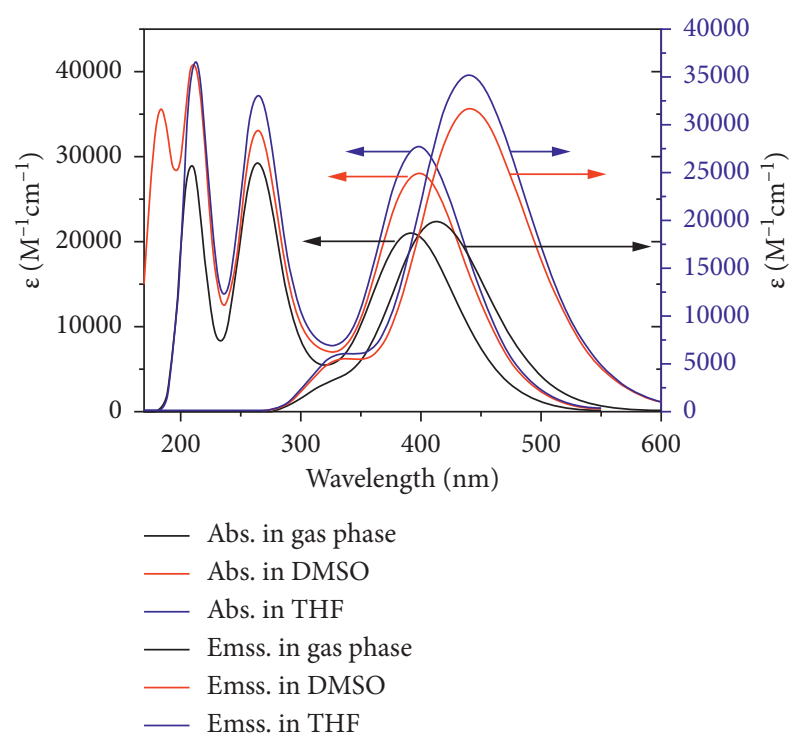

FIGURE 4: Calculated electronic absorption and emission spectra for the DDP molecule in the gaseous phase (in black), DMSO (in red), and THF (in blue). CAM-B3LYP/6-311G++ (d, p) was applied. polarity of the solvents. Because of the high polarity of DMSO compared to THF and gas phase, the $\lambda_{\max }$ emission of the DDP molecule in DMSO is red-shifted $(438 \mathrm{~nm})$ compared to that in THF $(437 \mathrm{~nm})$ and gas phase $(413 \mathrm{~nm})$. Due to the overlap between calculated absorption and emission spectra of the DDP molecule, a part of photons from the emission spectrum of the DDP molecule is reabsorbed via the inner filter effect. As presented in Table 4, the calculated electronic absorption and emission spectra of the DDP molecule in numerous solvents via victimization CAM-B3LYP/6-311G++ $(d, p)$ level of theory are in reasonable agreement with the experimental observation. The electronic transitions in THF were reconsidered according to previous data available to us. The calculated electronic absorption spectrum of DDP in THF is available at six possible electronic transitions at $398(f=0.5143), 330(f=0.0219), 314$ $(f=0.0448), \quad 310 \quad(f=0.0354), 265 \quad(f=0.4749), \quad$ and 211 $(f=0.5159) \mathrm{nm}$. Accordingly, three of the new values agree with experimental results. This was quoted in Table 2 showing an agreement between theoretical and experimental results. The first, second, and third electronic transitions correspond to the experimental peaks at 398, 330, and $314 \mathrm{~nm}$ arising from $\mathrm{HOMO} \longrightarrow \mathrm{LUMO}, \quad \mathrm{HOMO} \longrightarrow \mathrm{LUMO}+1, \quad$ and $\mathrm{HOMO}-1 \longrightarrow$ LUMO transitions.

The optimal DFT functional and the basis set for calculating the optical properties of the DDPA molecule were CAMB3LYP/6-311G++ (d, p). Hence, the calculated electronic UVVis absorption and emission spectra of the DDPA molecule in different solvents such as $\mathrm{CCl}_{4}, \mathrm{CH}_{3} \mathrm{Cl}, \mathrm{CH}_{2} \mathrm{Cl}_{2}$, acetone, and DMSO were compared with the CAM-B3LYP/6-311G++(d, p) level of theory. The obtained spectra are shown in Figure 5. The UV-Vis absorption spectra have two maximum absorption wavelengths assigned to $\pi-\pi^{*}$ and $n-\pi^{*}$ as shown in Figure 5. Depending on the polarity of various solvents, the two maximum absorption wavelengths of DDPA are shifted to a longer wavelength (red-shifted) once the polarity of the 
TABle 4: Experimental (Exp.) and theoretical (Th.) maximum absorption $\left(\lambda_{\mathrm{abs}}\right)$ and emission $\left(\lambda_{\text {emss. }}\right)$ wavelengths for the DDP molecule within DMSO and THF solvents. CAM-B3LYP/6-311G++ (d, p) was applied.

\begin{tabular}{lcccccccc}
\hline Solvents & \multicolumn{3}{c}{$\lambda_{\text {abs }}($ Exp.) $(\mathrm{nm})$} & \multicolumn{3}{c}{$\lambda_{\text {abs }}($ Th.) $(\mathrm{nm})$} & $\lambda_{\text {emss. }}($ Exp. $)(\mathrm{nm})$ & $\lambda_{\text {emss. }}(\mathrm{Th}).(\mathrm{nm})$ \\
\hline DMSO & 204 & 259 & 389 & 211 & 265 & 398 & 441 & 438 \\
THF & 334 & 365 & 424 & 314 & 330 & 398 & 439 & 437 \\
\hline
\end{tabular}

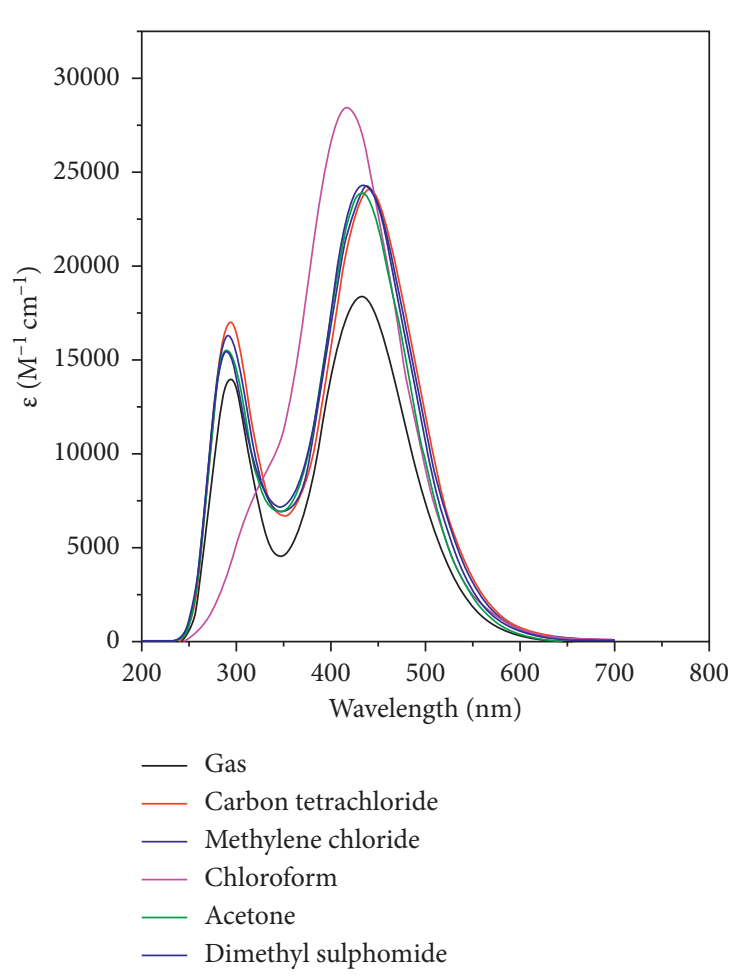

(a)

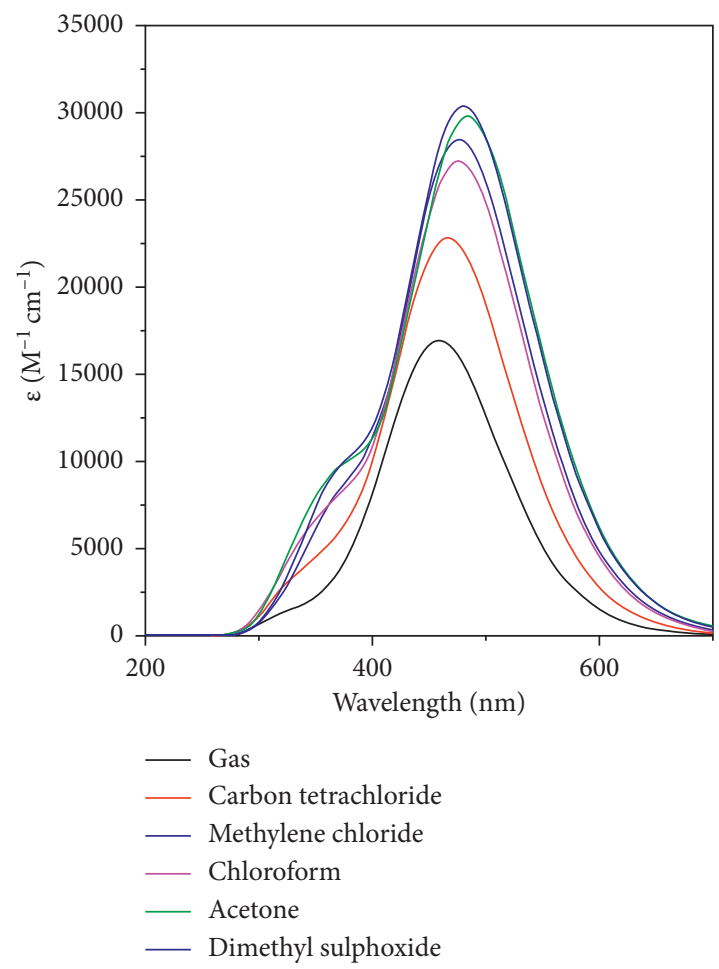

(b)

Figure 5: Calculated absorbance (a) and emission (b) spectra of the DDPA molecule in different solvents. The CAM-B3LYP/6-311G++ (d, p) level of theory was applied.

solvents is decreased as shown in Figure 5 and Table 5. For the DDPA molecular structure in numerous solvents, the emission spectra show only one band of maximum emission wavelength $\left(\lambda_{\text {max. }}\right)$ between 461 and $481 \mathrm{~nm}$, depending on the polarity of the solvents. Owing to the high polarity of DMSO compared to alternative solvents and gaseous phase, the $\lambda_{\max }$ emission of the DDPA molecule in DMSO is red-shifted (482 nm) compared to other solvents and gaseous phase. Due to overlapping between calculated electronic absorption and emission spectra of the DDPA molecule, inner filter effect leads to reabsorption of photons from the short-wavelength component of the emission spectrum. By comparing the experimental results of DDPA (Table 3) with the theoretical results for the same compound (Table 5), we find that the theoretical results agree with the experimental ones. By the comparison the absorption spectrum of compounds under study, as its absorption spectrum ranges (300 to $500 \mathrm{~nm}$ ) that match previously reported quinoline derivatives that have been studied in literature $[30,31]$ of showing absorbance in the range 280 to $510 \mathrm{~nm}$. So, there is an agreement between the theoretical calculations in this manuscript and the other previous research studies. Hence, the
TABle 5: Calculated maximum absorption $\left(\lambda_{\mathrm{abs}}\right)$ and emission wavelengths $\left(\lambda_{\text {ems }}\right)$ of the DDPA molecule in different solvents.

\begin{tabular}{lccc}
\hline Solvents & \multicolumn{2}{c}{$\lambda_{\text {abs. }}(\mathrm{nm})$} & $\lambda_{\text {ems. }}(\mathrm{nm})$ \\
\hline Gas & 295 & 433 & 461 \\
Carbon tetrachloride & 294 & 442 & 469 \\
Chloroform & 291 & 438 & 478 \\
Methylene chloride & - & 436 & 479 \\
Acetone & 289 & 432 & 480 \\
DMSO & 287 & 431 & 482 \\
\hline
\end{tabular}

CAM-B3LYP/6-311G++(d, p) level of theory is best for calculating UV-Vis absorption spectra of quinoline derivatives.

3.4. Molecular Electrostatic Potential (MESP) Maps. The molecular electrostatic potential (MESP) maps [27, 28] for DDP and DDPA molecular structures via applying the B3LYP/ 6-31G (d) [29, 32] level of theory are obtained. The graphical MESP maps are shown in Figure 6. At the surface of the studied molecular structure, the MESP is characterized via totally different colors as shown in Figure 6. In the MESP map, the red 

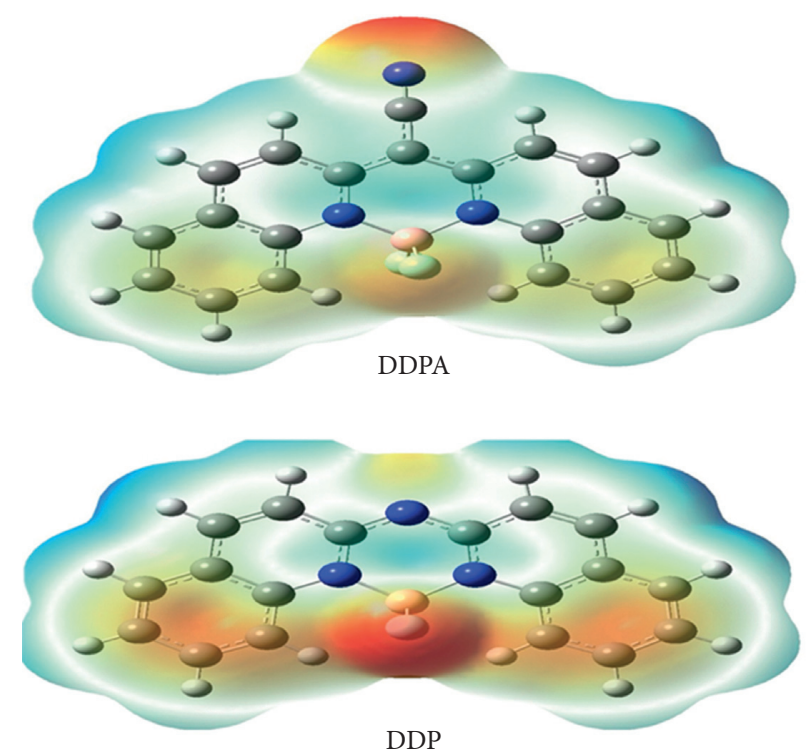

FIGURE 6: MESP maps for DDP and DDPA molecular structures using the B3LYP/6-31G (d) level of theory.

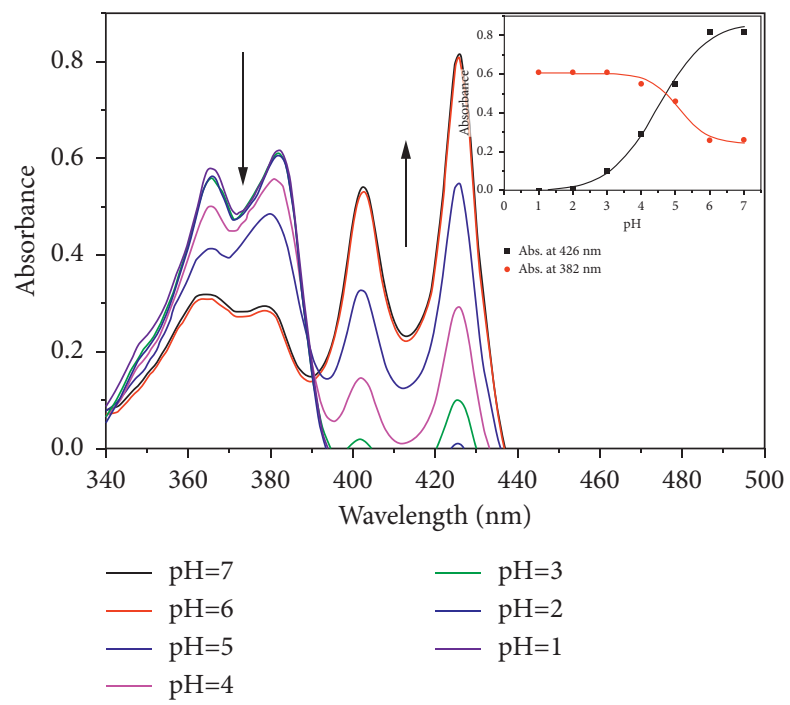

Figure 7: The electronic absorption spectra of $1 \times 10^{-5} \mathrm{M}$ for DDP dye at several $\mathrm{pH}$ values. The inset shows the plot of absorbance of $1 \times 10^{-5} \mathrm{M}$ for DDP dye versus $\mathrm{pH}$.

color regions correspond to negative MESP (electrophilic reactivity), the blue color sites refer to positive MESP (nucleophilic reactivity), and the green color parts relate to zero MESP. Therefore, the negative potential site in $\mathrm{DDP}$ is the $\mathrm{BF}_{2}$ group, as well as the positive potential regions in the DDP molecule are around the hydrogen atoms as bestowed in Figure 6. On the contrary, the negative potential site in DDPA is the $\mathrm{C}=\mathrm{N}$ cluster, as well as the positive potential regions within the same molecule are around the hydrogen atoms as bestowed in Figure 6.

3.5. Studying the Effect of $p H$ on the DDP Molecule in Methanol. It was noted during the study that the quinoline derivatives are affected by the acidic medium, so it was important to study the effect of the acidic medium on one of these compounds as an example to assess the extent of the effect of $\mathrm{pH}$ on the quinoline family. For the DDP molecule in methanol, the experimental electronic absorption spectra at different $\mathrm{pH}$ values are studied; the obtained spectra are shown in Figure 7. Due to protonation of $(=\mathrm{N})$ within the DDP molecule utilizing the acidic medium, the maximum absorption bands at 366 and $382 \mathrm{~nm}$ are decreased. At the same time, the maximum absorption bands at 403 and $426 \mathrm{~nm}$ are increased. The isosbestic point of the DDP molecule occurs at $391 \mathrm{~nm}$. According to the half-height technique and upon utilizing UV-spectrophotometric titration (Figure 7 inset), the ground-state protonation constant ( $\mathrm{pKa}$ ) was determined. From electronic absorption spectra of the DDP molecule, the magnitude of $\mathrm{pKa}$ is 4.72 . 


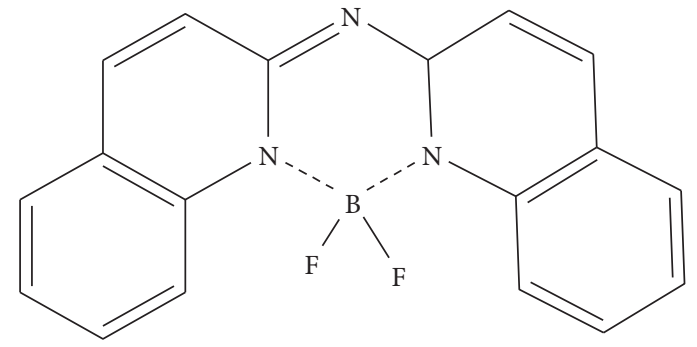

DDP

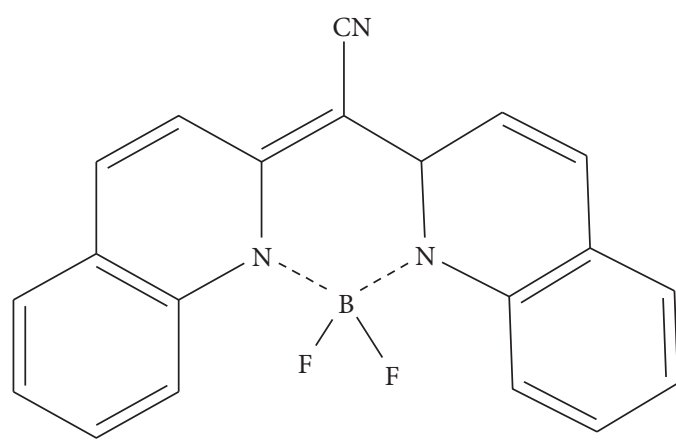

DDPA

FIgURE 8: The molecular structures of DDP and DDPA.

The excited-state protonation constant $\left(p K a^{*}\right)$ is calculated by using the following equation: $p K_{a}-p K_{a^{*}}=$ $2.1 \times^{-3}\left(\mathfrak{o}_{B H^{+}}-\mathfrak{o}_{B}\right)$, where $\left(\mathfrak{o}_{\mathrm{BH}^{+}}-\mathfrak{o}_{\mathrm{B}}\right)$ refers to the difference between the wavenumbers $\left(\mathrm{cm}^{-1}\right)$ of the electronic transition of the pure acidic and conjugate base. The $p K a^{*}$ value was found to be -0.95 indicating high basicity of the DDP molecule. Figure 8 shows the molecular structures of DDP and DDPA.

\section{Conclusion}

The molecular structures of the quinoline derivatives were optimized via applying the B3LYP/6-31G (d) level of theory. The electronic absorption and emission spectra of the DDP compound in gas, THF, and DMSO were calculated exploiting the time-dependent density functional theory (TD-DFT) at the CAM-B3LYP/6-31G ++(d, p) level. The calculated electronic absorption and emission spectra for DDP agree with experimental results. The experimental electronic absorption spectra for the DDP molecule in methanolic solutions of different $\mathrm{pH}$ values are studied. The molecular electrostatic potential (MESP) maps for DDP and DDPA molecular structures via applying the B3LYP/6-31G (d) level of theory are obtained.

\section{Data Availability}

The data used to support the findings of this study are available from the corresponding author upon request.

\section{Conflicts of Interest}

The authors declare no conflicts of interest.

\section{References}

[1] A. Lilienkampf, J. Mao, B. Wan, Y. Wang, S. G. Franzblau, and A. P. Kozikowski, "Structure-Activity relationships for a series of quinoline-based compounds active against replicating and nonreplicating Mycobacterium tuberculosis," Journal of Medicinal Chemistry, vol. 52, no. 7, pp. 2109-2118, 2009.

[2] S. Eswaran, A. V. Adhikari, I. H. Chowdhury, N. K. Pal, and K. D. Thomas, "New quinoline derivatives: synthesis and investigation of antibacterial and antituberculosis properties," European Journal of Medicinal Chemistry, vol. 45, no. 8, pp. 3374-3383, 2010.

[3] R. A. Mekheimer, M. A. Al-Sheikh, H. Y. Medrasi, and K. U. Sadek, "Advancements in the synthesis of fused tetracyclic quinoline derivatives," RSC Advances, vol. 10, no. 34, pp. 19867-19935, 2020.

[4] R. S. Keri and S. A. Patil, "Quinoline: a promising antitubercular target," Biomedicine \& Pharmacotherapy, vol. 68, no. 8, pp. 1161-1175, 2014.

[5] Team R. C., ĐCengel, Y. A. B., ĐCengel, M. A. Y. A., Boles, M. A., ĐCengel, Y. A. C., ĐCengel, J. M. Y. A., \& Cimbala J. M. (2012). T (No. 536. 7). M-H (2012). T (No. 536. 7). M-H, MILLS, Anthony F. Transferencia de calor. Irwin 1995., Payerle G. Scholar (4). Professional psychology;3:45.

[6] K. Kaur, M. Jain, R. P. Reddy, and R. Jain, "Quinolines and structurally related heterocycles as antimalarials," European Journal of Medicinal Chemistry, vol. 45, no. 8, pp. 3245-3264, 2010.

[7] S. Bongarzone and M. L. Bolognesi, "The concept of privileged structures in rational drug design: focus on acridine and quinoline scaffolds in neurodegenerative and protozoan diseases," Expert Opinion on Drug Discovery, vol. 6, no. 3, pp. 251-268, 2011.

[8] P. A. More and G. S. Shankarling, "Energy efficient Pfitzinger reaction: a novel strategy using a surfactant catalyst," New Journal of Chemistry, vol. 41, no. 21, pp. 12380-12383, 2017.

[9] A. L. Barry, "Procedure for testing antimicrobial agents in agar media: theoretical considerations," Antibiotics in Laboratory Medicine, pp. 1-26, Oxford Academic, Oxford, UK, 1986.

[10] A. Martin, M. Camacho, F. Portaels, and J. C. Palomino, "Resazurin microtiter assay plate testing of Mycobacterium tuberculosis susceptibilities to second-line drugs: rapid, simple, and inexpensive method," Antimicrobial Agents and Chemotherapy, vol. 47, no. 11, pp. 3616-3619, 2003.

[11] A. V. Deshpande, J. R. Rane, and L. V. Jathar, "Comparison of spectroscopic and lasing properties of different types of sol-gel glass matrices containing Rh-6G," Journal of Fluorescence, vol. 19, pp. 1083-93, 2009.

[12] C. Adamo and V. Barone, "Toward reliable density functional methods without adjustable parameters: the PBE0 model," The Journal of Chemical Physics, vol. 110, no. 13, pp. 61586170, 1999.

[13] A. V. Deshpande and U. Kumar, "Effect of method of preparation on photophysical properties of Rh-B impregnated sol-gel hosts," Journal of Non-crystalline Solids, vol. 306, no. 2, pp. 149-159, 2002. 
[14] D. Avnir, D. Levy, and R. Reisfeld, "The nature of the silica cage as reflected by spectral changes and enhanced photostability of trapped rhodamine 6G," Journal of Physical Chemistry, vol. 88, no. 24, pp. 5956-5959, 1984.

[15] A. V. Deshpande and E. B. Namdas, "Efficient lasing action of rhodamine 6G in Nafion membranes," Chemical Physics Letters, vol. 263, no. 3-4, pp. 449-455, 1996.

[16] A. V. Deshpande and R. R. Panhalkar, "Spectroscopic properties of coumarin 2 in $\mathrm{HCl}$ and $\mathrm{HNO}_{3}$ catalysed sol-gel glasses," Journal of Luminescence, vol. 96, no. 2-4, pp. 185-193, 2002.

[17] D. Avnir, V. R. Kaufman, and R. Reisfeld, "Organic fluorescent dyes trapped in silica and silica-titania thin films by the sol-gel method. Photophysical, film and cage properties," Journal of Non-crystalline Solids, vol. 74, no. 2-3, pp. 395-406, 1985.

[18] S. Tavker, P. Kumar P, H. R. Carlon, and M. E. Milham, "Isosbestic point: an application for aerosol spectrometry," Journal of Geophysical Research: Atmospheres, vol. 102, no. D25, pp. 30017-30022, 1997.

[19] M. J. van Staaden, H. Römer, and V. C. K. Couldridge, "1 A novel approach to hearing: the acoustic world of pneumorid. Complex worlds from simpler," Nervous System, vol. 335, 2004.

[20] H. R. Carlon, "Practical upper limits of the optical extinction coefficients of aerosols," Applied Optics, vol. 18, no. 9, pp. 1372-1375, 1979.

[21] H. R. Carlon, "Isosbestics in infrared aerosol spectra: proposed applications for remote sensing," Infrared Physics, vol. 21, no. 2, pp. 93-99, 1981.

[22] P. Chýlek, G. Videen, D. Ngo, R. G. Pinnick, and J. D. Klett, "Effect of black carbon on the optical properties and climate forcing of sulfate aerosols," Journal of Geophysical Research: Atmospheres, vol. 100, pp. 16325-16332, 1995.

[23] Frisch M., Trucks G. W., Schlegel H. B., Scuseria G. E., Robb M. A., Cheeseman J. R., et al. Gaussian 09 revision D. 012014.

[24] B. Miehlich, A. Savin, H. Stoll, and H. Preuss, "Results obtained with the correlation energy density functionals of Becke and Lee, Yang and Parr," Chemical Physics Letters, vol. 157, no. 3, pp. 200-206, 1989.

[25] S. U. Lee, "Influence of exchange-correlation functional in the calculations of vertical excitation energies of halogenated copper phthalocyanines using time-dependent density functional theory (TD-DFT)," Bulletin of the Korean Chemical Society, vol. 34, no. 8, pp. 2276-2280, 2013.

[26] J. Sun, G. Li, and W. Liang, "How does the plasmonic enhancement of molecular absorption depend on the energy gap between molecular excitation and plasmon modes: a mixed TDDFT/FDTD investigation," Physical Chemistry Chemical Physics, vol. 17, no. 26, pp. 16835-16845, 2015.

[27] E. Katchalski-Katzir, E. Haas, and I. Z. Steinberg, "Study of conformation and intramolecular motility of polypeptides in solution by a novel fluorescence method," Annals of the New York Academy of Sciences, vol. 366, pp. 44-61, 1981.

[28] S. A. Abdel-Latif and A. A. Mohamed, "Synthesis, spectroscopic characterization, first order nonlinear optical properties and DFT calculations of novel $\mathrm{Mn}(\mathrm{II}), \mathrm{Co}(\mathrm{II}), \mathrm{Ni}(\mathrm{II})$, $\mathrm{Cu}$ (II) and $\mathrm{Zn}$ (II) complexes with 1,3-diphenyl-4-phenylazo5-pyrazolone ligand," Journal of Molecular Structure, vol. 1153, pp. 248-261, 2018.

[29] S. A. El-Daly and K. A. Alamry, "Spectroscopic investigation and photophysics of a D- $\pi$-A- $\pi$-D type styryl pyrazine derivative," Journal of Fluorescence, vol. 26, no. 1, pp. 163-176, 2016.
[30] M. Khalid, M. A. Ullah, M. Adeel, M. Usman Khan, M. N. Tahir, and A. A. C. Braga, "Synthesis, crystal structure analysis, spectral IR, UV-Vis, NMR assessments, electronic and nonlinear optical properties of potent quinoline based derivatives: interplay of experimental and DFT study," Journal of Saudi Chemical Society, vol. 23, no. 5, pp. 546-560, 2019.

[31] G. C. Dos Santos, R. O. Servilha, E. F. de Oliveira, F. C. Lavarda, V. F. Ximenes, and L. C. da Silva-Filho, "Theoretical-experimental photophysical investigations of the solvent effect on the properties of green- and blue-lightemitting quinoline derivatives," Journal of Fluorescence, vol. 27, no. 5, pp. 1709-1720, 2017.

[32] M. Bourass, A. T. Benjelloun, M. Benzakour et al., "DFT and TD-DFT calculation of new thienopyrazine-based small molecules for organic solar cells," Chemistry Central Journal, vol. 10, pp. 67-11, 2016. 